\title{
PRODUCTOS NATURALES COMO ESTIMULADORES DEL SISTEMA INMUNOLÓGICO DE Litopenaeus vannamei, INFECTADO CON Vibrio parahaemolyticus ${ }^{1}$
}

\author{
Nelson Peña-Navarro ${ }^{2}$, Ruth Vargas-Cordero ${ }^{3}$, Alexander Varela-Mejías ${ }^{4}$
}

\begin{abstract}
RESUMEN
Productos naturales como estimuladores del sistema inmunológico de Litopenaeus vannamei, infectado con Vibrio parahaemolyticus. El objetivo de este trabajo fue determinar la respuesta inmunológica de Litopenaeus vannamei con manano-oligosacáridos (T1), ajo (T2) y un compuesto de extractos de plantas (T3) después de ser infectados con Vibrio parahaemolyticus. Se realizaron dos bioensayos con una duración de seis $\left(1 \times 10^{6}\right.$ UFC) y catorce $\left(3 \times 10^{6}\right.$ UFC) días en el Centro de Investigación en Ciencias del Mar y Limnología de la Universidad de Costa Rica durante el 2011. Para esta investigación se extrajeron 120 camarones para cada periodo experimental de fincas ubicadas en la Península de Nicoya. Al finalizar la dosificación de los productos se evaluó la ganancia de peso y la conversión alimenticia. Luego de la infección con V. parahaemolyticus se realizaron hemogramas, coagulación, bacteriología de hemolinfa y mortalidad acumulada. Los parámetros inmunológicos no mostraron diferencias estadísticas $(\mathrm{P}>0,05)$ entre tratamientos en ningún periodo, sin embargo a los seis días T1 mostró los mejores resultados con $41,07 \times 10^{5}$ hemocitos/ml; una coagulación de 34,40 s y $4,44 \times 10^{3} \mathrm{UFC} /$ $\mathrm{ml}$. En el periodo de catorce días T2 obtuvo los mejores valores $\left(55,76 \times 10^{5}\right.$ hemocitos $/ \mathrm{ml}$; una coagulación de 34,20 s y $\left.15,4 \times 10^{3} \mathrm{UFC} / \mathrm{ml}\right)$. La mortalidad acumulada se presentó a las diez horas de inoculación, hubo menor cantidad de muertes en T1 y T3 $(76,2 \%)$ a los seis días, mientras que a los catorce días fue para T1 $(93,2 \%)$. La ganancia de peso y la conversión alimenticia resultaron con diferencias estadísticas $(\mathrm{P}<0,05)$ solo para el bioensayo que se extendió por seis días, donde T2 presentó una biomasa de 54,3 g, un incremento en la ganancia de peso de 19,3\% y una conversión alimenticia de 1,4.
\end{abstract}

Palabras claves: Inmunología del camarón, inmunoestimulación, hemogramas, infección bacteriana, conversión alimenticia.

\begin{abstract}
Natural products as stimulators of immunological system in Litopenaeus vannamei, infected with Vibrio parahaemolyticus. The objective was to determine the immunological response of Litopenaeus vannamei using mannan-oligosaccharides (T1), garlic (T2) and a compound from plant extracts (T3) after being infected with Vibrio parahaemolyticus. Two bioassays were performed with duration of six $\left(1 \times 10^{6} \mathrm{CFU}\right)$ and fourteen $\left(3 \times 10^{6} \mathrm{CFU}\right)$ days in the Marine Sciences and Limnology Research Center, University of Costa Rica in 2011. Research used 120 shrimp for each experimental period, extracted from farms located in the Nicoya Peninsula. Weight gain and feed conversion were evaluated after product's dosage. After infection with $V$. parahaemolyticus, hemograms, coagulation, hemolymph's bacteriology and accumulated mortality analysis were made. Immunological parameters showed no statistical difference $(\mathrm{P}>0,05)$ between treatments in any period, however after six days, T1 showed $41,07 \times 10^{5}$ hemocytes $/ \mathrm{ml}$, coagulation of $34,40 \mathrm{~s}$ and $4,44 \times 10^{3} \mathrm{CFU} / \mathrm{ml}$. Throughout the fourteen day period, T2 obtained the best values $\left(55,76 \times 10^{5}\right.$ hemocytes $/ \mathrm{ml}$, coagulation of $34,20 \mathrm{~s}$ and $\left.15,4 \times 10^{3} \mathrm{CFU} / \mathrm{ml}\right)$. After 10 hours of inoculation, accumulated mortality presented fewer deaths in T1 and T3 $(76,2 \%)$ at six days, whereas at 14 days was $(93,2 \%)$ for T1. Weight gain and feed conversion presented statistical differences $(\mathrm{P}<0,05)$ only for the bioassay which lasted six days, where T2 showed a 54,3 $\mathrm{g}$ biomass, an increase in weight gain of $19,3 \%$ and feed conversion of 1,4 .
\end{abstract}

Key words: Shrimp immunology, immunostimulation, hemograms, bacterial infection, feed conversion.

\footnotetext{
1 Recibido: 17 de agosto, 2012. Aceptado: 1 de abril, 2013. Proyecto de Investigación "Análisis de alimentos utilizados en la producción acuícola en Costa Rica" \# 737-A7-214. Universidad de Costa Rica.

2 Universidad Técnica Nacional de Costa Rica. Apartado postal: 148-5400 Puntarenas.npena@utn.ac.cr (autor para correspondencia).

3 Universidad de Costa Rica. Apartado postal: 429-2070. ruth.vargas.cordero@gmail.com

4 Laboratorio de Patologías y Parasitología de Crustáceos (empresa privada). Barra Honda, Nicoya, Guanacaste, Costa Rica. alexander. varela@gmail.com
} 


\section{INTRODUCCIÓN}

Los organismos acuáticos han surgido como una importante fuente de alimento y trabajo en los principales países dedicados a este tipo de producción (Balcázar 2002). En este aspecto, la camaronicultura ha incrementado su producción en los últimos años, donde según la FAO (2010) durante el 2008 la producción de Litopenaeus vannamei en América constituyó el 80,7\% de la producción acuícola mundial y comercialmente se ha convertido en un producto muy importante, trascendiendo en el mercado internacional.

Al vislumbrarse la camaronicultura como un mercado promisorio, los productores han incrementado las densidades de cultivo, lo que ha ocasionado una reducción de la calidad de las aguas (Álvarez et al. 2000), esto provoca gran estrés en los camarones (Balcázar 2002) y genera un incremento en la ocurrencia de enfermedades infecciosas oportunistas (Gullian y Rodríguez 2002, Trujillo et al. 2005), entre estas las de tipo viral y bacteriana (Ibarra et al. 2003), producto del detrimento progresivo del sistema inmunológico (Gómez et al. 2001).

El impacto de las enfermedades en las producciones acuícolas ha generado grandes pérdidas económicas (Montserrat y Herrera 2000, Burge et al. 2007, Decamp et al. 2008), siendo las de tipo bacterial como Vibrio sp. (Gómez et al. 1998, Rojlorsakul et al. 1998, Kannapiran et al. 2009, Ganesh et al. 2010) una de las más importantes en los camarones, situación confirmada por Varela $(2011)^{5}$ para Costa Rica; las cuales son responsables de mortalidades de hasta un 100\% (Trujillo et al. 2005) y donde se han reportado pérdidas de hasta tres billones de dólares en las explotaciones de todo el mundo (Mayer 2010).

En los últimos años, también se ha promovido la producción de camarón de una forma sostenible, lo que ha fomentado en las operaciones de cultivo un desarrollo de manera responsable con el ambiente y con la sociedad (Cuéllar-Ánjel et al. 2010). Del mismo modo, la búsqueda de alternativas naturales eficientes contra enfermedades surgen de la necesidad de sustituir el uso de antibióticos, que como indican Haws et al. (2001), son dañinas si se usan de manera inadecuada, no solo por su efecto en la contaminación

Varela, A. 2011. Patología de camarones. Comunicación personal. Guanacaste, C. R. Coonaprosal R.L. del ambiente, sino también por el posible daño perjudicial en los seres humanos que consumen camarones con residuos de químicos en su organismo. Cuéllar-Ánjel et al. (2010) mencionan la necesidad de que el producto final esté libre de peligros químicos y biológicos para el consumidor y donde el proceso de producción se efectúa utilizando prácticas amigables al medio ambiente.

Como alternativa natural, Curiquén y González (2006) realizaron investigaciones con oligosacáridos, particularmente manano-oligosacáridos; donde mencionan que estos funcionan principalmente al cumplir roles inmunológicos y nutricionales en los animales. Asimismo en los últimos años, se ha promovido mundialmente una gran cantidad de trabajos que se han dedicado al estudio del uso de extractos de plantas, como una opción para reducir el uso excesivo de antibióticos utilizados en la alimentación.

Los extractos se han considerado como una alternativa para reemplazar los promotores de crecimiento y para mejorar la productividad animal sin incurrir en daños ambientales (Benchaar et al. 2007); donde se ha demostrado el efecto benéfico de una gran variedad de aceites esenciales sobre enfermedades bacterianas y principalmente contra las producidas por bacterias Gram negativas (Villamar 2000, Prieto et al. 2005) entre las que se encuentran las del género Vibrio sp.

El objetivo de la presente investigación fue determinar la respuesta inmunológica del camarón Litopenaeus vannamei, mediante el uso de tres productos naturales como inmunoestimulantes después de ser infectado con Vibrio parahaemolyticus.

\section{MATERIALES Y MÉTODOS}

Se realizaron dos bioensayos de seis (Bioensayo 1) y catorce días (Bioensayo 2) en el Centro de Investigación en Ciencias del Mar y Limnología (CIMAR) en la Ciudad de la Investigación, Universidad de Costa Rica, durante junio y agosto del 2011.

La infraestructura destinada al desarrollo de esta investigación consistió en un laboratorio de acuarios acondicionado con seis tanques de almacenamiento de aproximadamente 900 litros de capacidad cada uno, aireación suministrada por un blower de 2,5 hp y un compresor. Las unidades experimentales consistieron en peceras de vidrio de $40 \times 40 \times 40 \mathrm{~cm}$, para un total 
de 64 litros y de los cuales se utilizó solo el 78\% de la capacidad total. Las peceras fueron cubiertas con una tapa de malla plástica y marco de madera para evitar la fuga de animales y la caída de los mismos en otras peceras o al suelo.

El agua utilizada fue donada por el Parque Marino del Pacífico, la cual fue extraída del mar en la localidad de Puntarenas y filtrada a $70 \mu \mathrm{m}$; con una salinidad de $35 \mathrm{ppm}$. Esta se almacenó en seis tanques y diez reservorios con capacidad de 900 y 425 litros, respectivamente.

\section{Camarones experimentales}

Los juveniles de L. vannamei utilizados para el estudio se recolectaron en las fincas Cerro Mar 3 (primer ensayo) y Caraito 2 (segundo ensayo), ubicadas en la zona de Colorado de Abangares (10 16' 55" Latitud Norte 84 $57^{\circ}$ '42" Longitud Oeste), Guanacaste, Costa Rica. Previo a su recolección se analizó una muestra de diez camarones por medio de la metodología de análisis en fresco (Cuéllar 2008), se implementó el examen clínico como un mecanismo que avaló un estado de salud óptimo antes del traslado. La muestra para el estudio fue de 120 animales por ensayo distribuidas en 20 peceras; el primer experimento con rangos de pesos entre 7,83 a 10,00 g, con promedio de $8,85 \pm 0,59$ (media \pm D.E); el segundo con rangos de 6,67 a $8,67 \mathrm{~g}$, promedio de 7,80 $\pm 0,55$ (media \pm D.E).

\section{Aclimatización y acondicionamiento en acuarios}

Luego de recolectar los camarones en horas de la mañana $(6-7 \mathrm{am})$ y de manera aleatoria por medio de una atarraya, se acondicionaron lentamente en bolsas con agua filtrada. Esta fue modificada para que tuvieran en promedio $25,5^{\circ} \mathrm{C}$ de temperatura, $24 \mathrm{ppm}$ de salinidad y una saturación de oxígeno de $23,8 \mathrm{mg} / \mathrm{l}$.

$\mathrm{Al}$ recibir los camarones en el área experimental ubicada en el CIMAR, se aclimataron por espacio de dos días en dos reservorios de 425 litros y cubiertos con tapas de malla plástica. Las bolsas, que contenían el agua y los animales se vaciaron lentamente distribuyendo 60 individuos en cada uno. Luego se igualaron paulatinamente las temperaturas y salinidades del agua contenidas en las bolsas y acondicionadas previamente en el laboratorio, las cuales presentaban una temperatura de $27^{\circ} \mathrm{C}$, una salinidad de $35 \mathrm{ppm}$ y una concentración de oxígeno disuelto de $6 \mathrm{mg} / \mathrm{l}$.
Luego de la aclimatización, se trasladaron los animales aleatoriamente a las peceras que poseían aireación y temperatura controlada, la primera producida por un sistema central de ventilación y distribuida mediante la utilización de piedras difusoras; mientras el segundo por medio de termostatos. El primer bioensayo presentó rangos de oxígeno entre 4,24 y $4,39 \mathrm{mg} / \mathrm{l}$, con promedio $4,33 \pm 0,04$ (media \pm D.E), temperatura de 29,46 y $30,28^{\circ} \mathrm{C}$, con promedio $29,97 \pm 0,21$ (media \pm D.E); mientras que el segundo bioensayo mostró rangos de oxígeno de 4,68 y 4,95 $\mathrm{mg} / 1$, con promedio $4,81 \pm 0,84$ (media \pm D.E), temperatura de 29,17 y $30,20^{\circ} \mathrm{C}$, con promedio $29,54 \pm 0,34$ (media \pm D.E); en ambos casos la salinidad fue de 35 ppm. Para medir el oxígeno y la temperatura se utilizó un oxigenómetro portátil, mientras que la salinidad se midió con un refractómetro.

Con el fin de mantener las condiciones óptimas de la calidad del agua, se realizó un recambio manual diario del $15 \%$, sifoneando desde el fondo, lo que mantuvo constantes los siguientes parámetros durante la alimentación: $\mathrm{pH}, 7,86 \pm 0,08$ (media \pm D.E.); $\mathrm{NH}_{3}$, $\pm 1 \mathrm{ppm} ; \mathrm{NH}^{3-}$ y $\mathrm{NH}^{2-}, 0$ ppm. Además, los camarones fueron sometidos a un fotoperiodo de $12 \mathrm{~h}$ de luminosidad y $12 \mathrm{~h}$ de oscuridad (inicio a las 6:00 h y finalización a las 18:00 h).

\section{Preparación de dietas y régimen de alimentación}

Durante los periodos experimentales de catorce y seis días, los camarones fueron alimentados con los tratamientos definidos por la mezcla del concentrado comercial (Cuadro 1) y los diferentes productos naturales seleccionados, donde se dosificó de acuerdo a la recomendación de las casas fabricantes.

Las dietas, conformadas por el alimento balanceado, los aditivos comerciales y el aceite de pescado que se utilizó para facilitar el proceso de recubrimiento, se prepararon individualmente de acuerdo a las recomendaciones para cada uno de los aditivos. A cada uno se le agregó el aceite y luego el alimento balanceado se combinó con la preparación anterior. Adicionalmente se formuló una dieta control a partir de alimento concentrado y aceite de pescado. Con base en lo anterior, 150 gramos de alimento balanceado fue preparado por triplicado, donde individualmente cada uno de ellos contenía 0,45 g de manano-oligosacáridos, $3 \mathrm{~g}$ de ajo molido y $0,3 \mathrm{~g}$ de extracto de plantas; todas adicionadas con $10 \mathrm{ml}$ de aceite de pescado. Posterior a 
Cuadro 1. Perfil nutricional del alimento comercial utilizado para alimentar a L. vannamei en los periodos experimentales de seis y catorce días. Costa Rica. 2011.

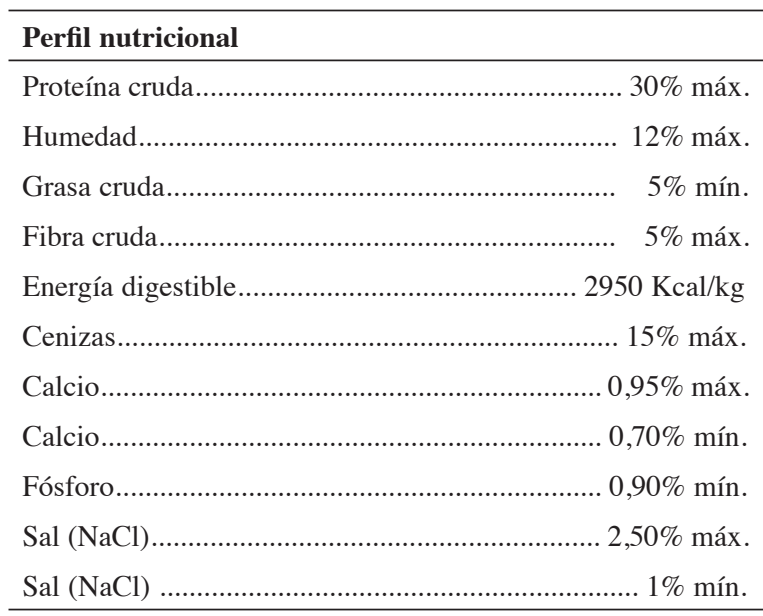

la preparación, se secó el alimento durante 20 min. en un horno a $60^{\circ} \mathrm{C}$; luego se dejó reposar a temperatura ambiente por otros $20 \mathrm{~min}$. y finalmente se llevó a $4^{\circ} \mathrm{C}$ durante $5 \mathrm{~min}$., con la finalidad de acelerar el proceso de secado. Por último, las dietas fueron empacadas en bolsas plásticas dobles y almacenadas en recipientes plásticos para conservar sus características nutricionales.

Los camarones de cada pecera fueron alimentados con un equivalente al $4 \%$ del peso vivo; donde se les suministró diariamente dos veces, a las 9:00 y 17:00 h.

\section{Tratamientos}

Se utilizaron cuatro tratamientos, uno como control y tres productos cuyos ingredientes principales son extractos obtenidos a partir de plantas y levaduras. Fueron seleccionados de acuerdo a sus cualidades para promover la actividad del sistema inmunológico (Curiquén y González 2006) y por poseer funciones antibactericidas (Prieto et al. 2005). Los anteriores tratamientos se describen a continuación:

T0: Alimento comercial (control) + aceite de pescado $(66,4 \mathrm{ml} / \mathrm{kg})$.

T1: Alimento comercial + manano-oligosacáridos (Saccharomyces cerevisiae) $(3 \mathrm{~g} / \mathrm{kg})+$ aceite de pescado $(66,4 \mathrm{ml} / \mathrm{Kg}$.).

T2: Alimento comercial + ajo (Allium sativum) $(20 \mathrm{~g} / \mathrm{kg})+$ aceite de pescado $(66,4 \mathrm{ml} / \mathrm{kg})$.
T3: Alimento comercial + mezcla de extractos de plantas $(2 \mathrm{~g} / \mathrm{kg})$, cada gramo contiene $=$ Azadirachta indica (270mg), Eclipta alba (135 mg), Phyllanthus amarus $(135 \mathrm{mg})$, Terminalia chebula (135 mg), Yasada bhasma (100 mg), Cichorium intybus (113 mg), Terminalia arjuna $(56 \mathrm{mg})$, Solanum nigrum $(56 \mathrm{mg})$ + aceite de pescado $(66,4 \mathrm{ml} / \mathrm{kg})$.

\section{Examen clínico y análisis en fresco}

Este procedimiento se realizó con base en el protocolo sugerido por Cuéllar (2008), donde se examinaron diez animales y a estos se les observó el color, tamaño del cuerpo comparado con el resto de la población (enanismo), expansión de cromatóforos, deformidad en rostro, abdomen o apéndices, flexión del músculo abdominal, color de las branquias (amarillas, marrón o negras), color de los apéndices (pereiópodos, pleópodos y urópodos), entre otros.

Seguidamente y después de revisar la condición fisiológica inicial de los camarones, se enviaron las muestras para el análisis en fresco de los camarones al Laboratorio de Patología y Microbiología de la Cooperativa COONAPROSAL R.L. en Colorado de Abangares, Guanacaste. Se siguió la técnica descrita por Morales (2008) y mediante un microscopio compuesto con objetivos de 4, 40, y $100 \mathrm{X}$, se buscaron alteraciones causadas por parásitos y patógenos en las branquias, hepatopáncreas, intestino y músculo.

\section{Cepas de Vibrio parahaemolyticus}

Se recibió la donación de las suspensiones de Vibrio parahaemolyticus por parte del Laboratorio de Bacteriología Médica de la Escuela de Microbiología de la Universidad de Costa Rica, las cuales fueron obtenidas a partir de la cepa ATCC 17802.

Se inocularon los camarones inyectándoles una suspensión bacteriana, obtenida a partir de la dilución en solución salina estéril de un concentrado bacterial al estándar de turbidez 0,5 de Mc Farland. Los camarones se inocularon mediante inyección intramuscular, entre el tercer y cuarto segmento abdominal con una jeringa estéril de 1 cc y con aguja de calibre $29 x^{1 / 2}$ (evitó traumatismos excesivos). Se utilizaron $20 \mathrm{mi}-$ crolitros (Rojas 2011) ${ }^{6}$ de una solución de bacterias de

Rojas N. 2011. Bacteriología (entrevista). San José, C. R. Universidad de Costa Rica. 
$0,5 \times 10^{8} \mathrm{UFC} / \mathrm{ml}$ (ensayo 1 ) y $1,5 \times 10^{8} \mathrm{UFC} / \mathrm{ml}$ (ensayo 2), los cuales contenían $1,0 \times 10^{6}$ y $3,0 \times 10^{6}$ UFC/camarón respectivamente.

\section{Parámetros inmunológicos}

Se realizaron análisis de hemograma total, coagulación de la hemolinfa y bacteriología en camarones moribundos, los cuales presentaban cambio en el comportamiento al inclinarse de medio lado, observándose diferencias en la coloración debido a los procesos de necrosis e infiltración hemocítica en la región inoculada.

\section{Hemograma}

Se empleó la técnica descrita por Cuéllar (2008), se extrajo hemolinfa del seno cardíaco e inmediatamente se procedió al montaje en una cámara de Neubauer para realizar el conteo total de hemocitos $(\mathrm{CTH})$ al utilizar un microscopio óptico. El número de hemocitos totales es expresado en millones de células por mililitro.

\section{Tiempo de coagulación de hemolinfa}

Se empleó la técnica recomendada por Varela $(2011)^{5}$, que consistió en la extracción de hemolinfa del hemocele de animales a los que se les sometió a una mínima manipulación para evitar estrés. Se introdujo la jeringa descartable de insulina entre los dos quintos pereiópodos, en un ángulo de aproximadamente $30^{\circ}$. La aguja penetró únicamente la cutícula y el tejido subyacente, debido a la superficialidad del hemocele; inmediatamente se colocaron dos o tres gotas de hemolinfa en un portaobjetos, y se agitó con la aguja de la misma jeringa, hasta evidenciar la formación de coágulos.

\section{Bacteriología de hemolinfa}

Se empleó la técnica descrita por Cuéllar (2008). Una vez inoculados los $100 \mu \mathrm{l}$ de muestra sobre el agar elegido y en condiciones asépticas se extendió circularmente mediante el uso de un asa de Drigalski previamente flameada, para obtener una distribución homogénea del inóculo. Seguidamente se invirtió la caja de Petri y se incubó a una temperatura de $35^{\circ} \mathrm{C}$ por 24 horas. Se revisó la presencia o ausencia de bioluminiscencia cada 12 horas. Posteriormente se contaron las unidades formadoras de colonias (UFC) que se presentaron en cada placa, para lo anterior se utilizó como método la observación directa (a trasluz).

\section{Mortalidad acumulada (M.A.)}

Después de inoculados los camarones y al mostrar síntomas como inclinación de medio lado, nado errático, poca reacción o coloración rojiza, se contabilizaron las muertes de animales a las 5 y 10 h post-infección, donde se obtuvieron los porcentajes de acuerdo a la siguiente fórmula:

$$
\text { M.A. }(\%)=\frac{\text { No. de animales muertos }}{\text { No. de animales inoculados }} \times 100
$$

\section{Parámetros zootécnicos}

\section{Ganancia de peso (GP)}

Se pesaron los animales de cada pecera con una balanza electrónica con una precisión de $0,1 \mathrm{~g}$ al inicio y final de cada experimento. Posteriormente se obtuvo la diferencia y se calculó el porcentaje de ganancia de peso con respecto al inicial. La fórmula utilizada fue la siguiente:

$$
\mathrm{GP}(\%)=\frac{(\mathrm{Pf}-\mathrm{Pi}) \times 100}{\mathrm{Pi}}
$$

Donde:

GP (\%): Porcentaje de ganancia de peso total; Pi: Peso inicial; Pf: Peso final.

\section{Conversión alimenticia (C.A.)}

Se pesó por pecera la cantidad de alimento suministrado a los camarones en una balanza electrónica con una precisión de $0,001 \mathrm{~g}$. Al final de cada periodo experimental se contabilizó el total de alimento suministrado diariamente. Igualmente, los camarones se pesaron procurando eliminar el exceso de agua que los cubría y se registró la información. Luego el valor acumulado del consumo de alimento concentrado se dividió por la ganancia de peso final registrada por pecera. 
La fórmula empleada para medir este parámetro fue la siguiente:

$$
\text { C.A. }=\frac{\text { Alimento consumido }}{\text { Ganancia de peso }}
$$

\section{Análisis estadístico}

Se generó la información al emplear un diseño de bloques completos al azar, donde los bloques correspondían a la gradiente ocasionada por la luminosidad (fotoperiodo) y en donde se utilizaron cinco bloques. Cada uno correspondió a un nivel de cada estante con cuatro unidades experimentales distribuidos equitativamente y con cinco repeticiones.

Las variables cuantitativas se evaluaron por pecera, las cuales fueron peso final, ganancia de peso, conversión alimenticia, porcentaje de mortalidad acumulada a las 5 y 10 horas post-infección, conteo de hemocitos total, tiempo total de coagulación de la hemolinfa y conteo bacteriológico en hemolinfa.

Los datos se procesaron por medio de un análisis de varianza ANOVA, con el procedimiento GLM del programa estadístico SAS (2003). La ecuación estadística empleada fue la siguiente:

$$
\mathrm{Y}_{\mathrm{ik}}=\mu+\mathrm{b}_{\mathrm{j}}+\mathrm{T}_{\mathrm{k}}+\mathrm{e}_{\mathrm{ik}}
$$

Dónde:

$\mathrm{Y}_{\mathrm{jk}}=$ Variables de respuesta de $\mathrm{j}$-ésima unidad experimental asociado al k-ésimo tratamiento.

$$
\begin{aligned}
\mu & =\text { Media general. } \\
\mathrm{b}_{\mathrm{j}} & =\text { Efecto del j-ésimo bloque. } \\
\mathrm{T}_{\mathrm{k}} & =\text { Efecto del k-ésimo tratamiento. } \\
\mathrm{e}_{\mathrm{jk}} & =\text { Error experimental. }
\end{aligned}
$$

Se realizó un análisis comparativo de las medias entre tratamientos con la prueba de Duncan, donde se consideró una significancia de $\alpha=0,05$.

\section{RESULTADOS Y DISCUSIÓN}

De acuerdo al examen clínico y análisis en fresco inicial que se efectuó en ambos grupos de camarones, los resultados mostraron niveles diferentes de infestación de gregarinas, desde ninguna detección hasta en algunos casos un número mayor de 100 gregarinas por campo visual. Se presentó un nivel de ectoparásitos leve en lamelas branquiales con presencia de Zoothamnium sp. y Epistylis sp., sin melanosis o necrosis asociada.

De acuerdo a la información anterior y lo descrito por Cuéllar (2008) se concluyó que los animales presentaban una condición sanitaria general apta para el inicio de los experimentos. Los mismos, estaban libres de la enfermedad que se pretendía reproducir y sin signos clínicos que demostraran la presencia de otra patogenicidad.

Para las variables que se determinaron en los bioensayos 1 (seis días) y 2 (catorce días), que correspondían a los parámetros inmunológicos, no se determinaron diferencias estadísticas entre tratamientos $(\mathrm{P}>0,05)$.

\section{Hemograma}

Después de seis días de suministrar los diferentes tratamientos, el conteo total de hemocitos fue mayor en T1 al obtener $41,07 \pm 7,56 \times 10^{5} \mathrm{cel} / \mathrm{ml}$. En este caso T2 $\left(35,29 \pm 9,25 \times 10^{5} \mathrm{cel} / \mathrm{ml}\right)$ obtuvo el conteo más bajo (Figura 1A). A pesar de lo anterior, la variación de los datos obtenidos no demuestra una diferencia numérica marcada, sin embargo, al analizar el efecto producido por el tratamiento control (T0) se observa en promedio mayor cantidad de hemocitos presentes en la hemolinfa que las dietas que contenían aditivos adicionales, como fue el caso del ajo y los extractos de plantas. Lo anterior es contrario a lo que se esperaba, principalmente debido a que de manera preliminar los tratamientos T2 y T3 debieron mostrar mejores resultados, de acuerdo a su composición y características principales; esto asociado a lo expuesto por Prieto et al. (2005) que indica que la función más destacada del ajo es la actividad antimicrobiana.

Por otro lado, durante el periodo de catorce días el conteo más alto de hemocitos obtenido del hemograma fue para el tratamiento que contenía ajo con 55,76 \pm $2,41 \times 10^{5} \mathrm{cel} / \mathrm{ml}$. Sin embargo se presentó una diferencia con respecto a T0 de alrededor de un $26,5 \%$. Los tratamientos compuestos por T1 y T3 mostraron valores inferiores respecto a T0 y T2; por otro lado, hay similitud entre los valores promedios obtenidos de T1 $(36,55 \pm$ $\left.9,09 \times 10^{5} \mathrm{cel} / \mathrm{ml}\right)$ y T3 $\left(36,84 \pm 12,65 \times 10^{5} \mathrm{cel} / \mathrm{ml}\right)$, donde se obtuvo una diferencia menor al 1\% (Figura 1B). 

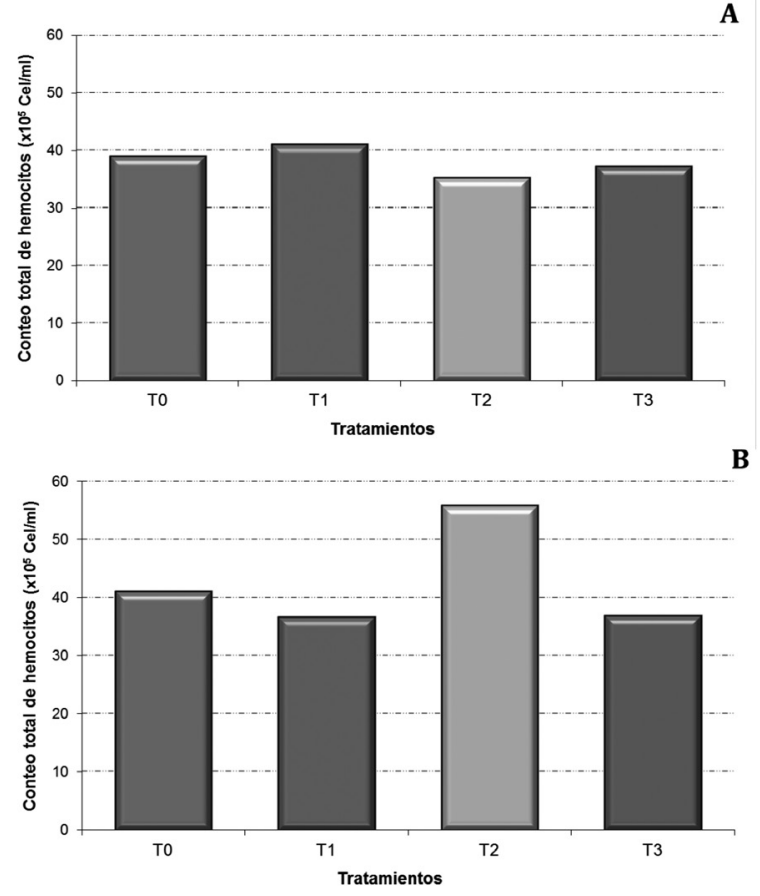

Figura 1. Medias de los conteos totales de hemocitos realizados en Litopenaeus vannamei infectados con Vibrio parahaemolyticus y después de ser alimentados con una dieta control (T0), manano-oligosacáridos (T1), ajo (T2) y extractos de plantas (T3). Costa Rica. 2011.

A) Infección tras seis días donde se inyectaron $1 \times 10^{6} \mathrm{UFC} / \mathrm{ca}-$ marón. B) Infección tras catorce días donde se inyectaron $3 \times 10^{6}$ UFC/camarón.

Por efecto de las bacterias patógenas que fueron inoculadas a nivel muscular, se dio una disminución de la cantidad de hemocitos presentes en la hemolinfa debido a la migración de estos, al punto donde se promovió la afectación y como respuesta inmunológica, en concordancia con lo descrito en la literatura (Burgents et al. 2005, Yeh y Chen 2008). Del proceso anterior resultan la fagocitosis, encapsulación, nodulación, activación del sistema proPo, liberación de péptidos antimicrobianos, lisozima, entre otros (Chang et al. 2000, Johansson et al. 2000, Rodríguez y Le Moullac 2000, Cerenius y Söderhäll 2004, Jiravanichpaisal et al. 2006, Burge et al. 2007, Dantas et al. 2009), lo que causó un proceso inflamatorio (Smith et al.2003). Lo anterior está asociado a las principales funciones de los hemocitos, al cicatrizar heridas e iniciar el proceso de coagulación (Rodríguez y Le Moullac 2000), y como recursos utilizados para contener la propagación de partículas infecciosas que lograrán entrar al hemocele (Smith et al. 2003).

Como respuesta a la presencia de microorganismos se da una disminución de los hemocitos pero después de algún tiempo vuelven a la normalidad ( $\mathrm{Ji}$ ravanichpaisal et al. 2006), situación que no se logró determinar en los ensayos de este estudio, ya que no fue posible realizar los hemogramas a través del tiempo, principalmente debido a la velocidad de reacción de los camarones ante la infección.

Por otro lado, los estudios realizados donde se utilizan inmunoestimulantes han logrado afectar los conteos de hemocitos (Smith et al. 2003), misma respuesta observada para los productos utilizados en la presente investigación, donde se determinó un aumento hemocitario a los catorce días de T2 en comparación a los otros tratamientos. A la vez, se presentó el mismo efecto por parte de T1 a los seis días, pero que no sobrepasó en más del $13 \%$ a los otros productos evaluados como inmunoestimulantes. Lo anterior se podría deber a una rápida activación inmunológica de los camarones o bien, a un mejor desarrollo y producción de células en el órgano hematopoyético, que según Johansson et al. (2000) y Jiravanichpaisal et al. (2006), ya está demostrado que es el órgano productor de hemocitos y que estos se desprenden de forma continua pero a niveles variables en la circulación y después de su maduración.

La investigación ejecutada por Dantas et al. (2009), donde se realizó conteo total de hemocitos en crustáceos mostraron una disminución considerable después de la inyección de bacterias. Por otro lado, Burge et al. (2007) expusieron una disminución del $45 \%$ en las primeras cuatro horas, adicionadas a un $23 \%$ a las 48 h post-infección. Lo anterior aunado a lo publicado por Rodríguez et al. (2000), quienes mostraron valores finales de hasta $5 \times 10^{6}$ hemocitos $/ \mathrm{ml}$, lo que coincidió con los resultados expuestos en ambos bioensayos; pero determinados por una respuesta fisiológica que varía individualmente de acuerdo a la respuesta ante la infección, estrés ambiental o a la actividad endocrina durante el ciclo de muda (Johansson et al. 2000, Dantas et al. 2009). Lo anterior se podría comparar a lo observado en este estudio donde se presentó en los animales muda, melanización y estrés 
de manejo asociado principalmente a la expansión de cromatóforos.

\section{Coagulación}

Al comparar la coagulación obtenida de los diferentes tratamientos aplicados en los camarones evaluados durante el primer trabajo experimental, resultó el promedio menor para la dieta de T1 $(34,40 \pm 9,73 \mathrm{~s})$. Por otro lado, los tratamientos T0, T2 y T3 muestran valores muy similares y no se encontró diferencias estadísticas entre tratamientos ( $\mathrm{P}>0,05): 38,20 \pm 6,90$ s; $39,00 \pm 21,17$ s y $39,10 \pm 8,73 \mathrm{~s}$; para cada uno respectivamente.

Con respecto al tiempo de coagulación evaluado en el segundo periodo, hubo un incremento sustancial de este aunque sin diferencia estadística en el tratamiento compuesto por $\mathrm{T} 1$ con respecto a los otros ingredientes utilizados, pero dentro del valor permi-

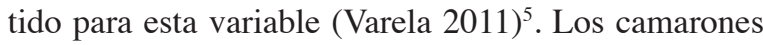
alimentados con $\mathrm{T} 1$ duraron 48,50 $\pm 25,01 \mathrm{~s}$ para lograr la coagulación de la hemolinfa; a la vez T3 provocó una disminución de 9,50 s con respecto a T1. La coagulación más rápida fue para el ajo $(34,20 \pm 18,14$ s) aunque la diferencia presentada con respecto al tratamiento control fue alrededor de un segundo $(32,25$ $\pm 18,63 \mathrm{~s}$ ), siendo prácticamente semejantes pero con una mejor respuesta en relación al tratamiento donde se suministró manano-oligosacáridos.

Aunque no se encontró información detallada del tiempo mínimo para determinar una coagulación apropiada en camarones, Varela $(2011)^{5}$ menciona que lo ideal es un minuto de tiempo, aunque indica que algunos especialistas permiten hasta minuto y medio. Dado lo anterior y según las pruebas realizadas los tratamientos que tenían manano-oligosacáridos y ajo mostraron los mejores valores, el primero en periodos cortos y el segundo en periodos prolongados. Dado lo anterior y en vista de la importancia de esta variable para preservar el estado de salud en L. vannamei, la disminución en el tiempo de coagulación asociada T2 y utilizado en periodos mayores a catorce días podría ser la mejor opción, lo que coincide con las conclusiones presentadas por Prieto et al. (2005).

Unido a esto, la importancia de la coagulación radica en que es una reacción que evita la pérdida de hemolinfa a través de las heridas (Lee y Söderhäll 2002) y ayuda en la captura de microbios que ingresan, a la vez que reducen su propagación por todo el hemocele (Jiravanichpaisal et al. 2006). Además, el tiempo de coagulación está relacionado directamente con los niveles de patógenos invasores que ingresan generalmente por medio de heridas, donde se genera, una activación secuencial de los factores de coagulación que finalizan con la formación de coágulos (Lee y Söderhall 2002).

\section{Unidades formadoras de colonias (UFC)}

Al analizar la cantidad de UFC en el bioensayo 1, el tratamiento que mostró los conteos mayores fue para $\mathrm{T} 1$ con $4,44 \pm 8,10 \times 10^{3} \mathrm{UFC} / \mathrm{ml}$, igualmente, se observó una disminución de UFC para el tratamiento control, ajo y extractos de plantas con respecto a $\mathrm{T} 1 \mathrm{de}$ 39,46 y $56 \%$, respectivamente; a pesar de lo anterior los valores fueron similares entre sí $(\mathrm{P}>0,05)$.

A la vez, en el bioensayo 2, los resultados mostraron una alta diferencia en los valores obtenidos de T2 y T3. T3 presentó un conteo de alrededor de 3,40 $\pm 2,77 \times 10^{3} \mathrm{UFC} / \mathrm{ml}$ de hemolinfa, lo que representó alrededor del $22 \%$ del valor obtenido en T2. Lo anterior reveló una aparente resistencia de los animales más elevada hacia las bacterias cuando se utilizó el alimento suministrado con ajo. Sin embargo, en T1 y T0 se observaron valores similares a T2 $\left(15,4 \times 10^{3}\right.$ $\left.\pm 20,65 \times 10^{3}\right)$, con una diferencia menor a 25 y $38 \%$ respectivamente. A los catorce días fue evidente una menor capacidad de reacción por parte del tratamiento que contenía la combinación de extractos de plantas en comparación a la información obtenida de los otros productos.

Se determinó que los camarones que presentaron los conteos promedios más altos obtuvieron una mayor resistencia, lo que podría deberse a una mayor reproducción y distribución de las bacterias por el organismo de los camarones para lograr su deceso, lo anterior coincidió con Roque et al. (1998) donde según estos, las bacterias se multiplican y producen toxinas letales que si no son eliminadas por los camarones causan la muerte. De acuerdo a Pantoja (2005), quien indica que niveles altos de bacterias abruman el sistema inmune del camarón, lo que provoca que sucumban rápidamente a la enfermedad; se podría considerar que T1 y T2 lograrían presentar una mayor fortaleza inmunológica post-infección a los seis y catorce días, respectivamente. 
La capacidad inhibitoria del crecimiento de las bacterias por parte de la hemolinfa, cuando se ejecuta su cuantificación a través del tiempo, es analizada por Rodríguez y Le Moullac (2000). En este sentido, algunos estudios muestran como a través del tiempo la actividad antimicrobiana de la hemolinfa puede lograr disminuir la cantidad de patógenos presentes al aplicar un producto con propiedades inmunoestimulantes o al causar una determinada respuesta inmune, como por ejemplo los glucanos, S. cerevisiae (Scholz et al. 1999), sulfuro (Hsu y Chen 2007), carragenatos (Yeh y Chen 2008), entre otros.

Durante el conteo de las bacterias se observaron casos de crecimiento de colonias amarillas y verdes en TCBS, probablemente debido al cambio de $\mathrm{pH}$ generado por el uso de sucrosa producto de la contaminación de otras bacterias (Cuéllar 2008). Esto podría deberse a la población diversa de bacterias fermentadoras de sucrosa presente en los tejidos del camarón o bien, por la contaminación de bacterias localizadas en el entorno (Gómez et al. 1998) que lograran contaminar las placas antes de colocarlas en la incubadora. Sin embargo, un estudio donde se infectó a $L$. vannamei por medio de un baño con $V$. parahaemolyticus indicó que al realizar el conteo en TCBS, alrededor del $20 \%$ del total de Vibrio sp. formó colonias amarillas (Roque et al. 1998), lo que indicaría una alta probabilidad de crecimiento de este tipo de bacterias bajo estas condiciones.

\section{Mortalidad acumulada}

Las medias de la mortalidad acumulada que se presentó en el análisis donde se inyectó $1 \times 10^{6} \mathrm{UFC} /$ camarón, mostraron una alta similitud $(\mathrm{P}>0,05)$. entre todos los tratamientos a las 5 y $10 \mathrm{~h}$ post-infección. Al registrar las muertes de camarones a las $5 \mathrm{~h}$ existió menos de un $7 \%$ de fallecimientos, donde $\mathrm{T} 3$ mostró alrededor de un $6 \%$ contrario a $\mathrm{T} 1$ que no presentó fatalidades (Figura 2A). Para T0 y T2 la cantidad de animales afectados mortalmente por el inóculo fue igual $(3,2 \%)$. Por otro lado, se mantuvo la relación existente de mortalidad acumulada entre tratamientos después de trascurridas 10 h desde el inicio de la infección (76 a 79\%), a excepción del tratamiento control que parece que sufrió a través del tiempo mayor efecto negativo de las bacterias, ya que alrededor del $86 \%$ de los animales murieron.

Cuando se inocularon con $3 \times 10^{6} \mathrm{UFC} /$ camarón, y al tener una mayor concentración de bacterias, se observó que la mortalidad acumulada a las $5 \mathrm{~h}$ postinfección, presentó porcentajes altos de decesos en casi todos los tratamientos, alcanzando en algunos casos valores cercanos al $50 \%$. Los menores porcentajes de fallecimientos se dieron para T3 (34\%) y T0 (37\%), mientras que los tratamientos $\mathrm{T} 2$ y $\mathrm{T} 1$ presentaron respectivamente 45 y $47 \%$ de muertes respecto al número inicial (Figura 2B). Luego de $10 \mathrm{~h}$ de exposición al inóculo, se dio un $100 \%$ de animales fallecidos en los tratamientos control y el representado por extractos de plantas, mientras que en T1 y T2 la mortalidad acumulada estuvo entre el 93 y 96\%, observándose una leve resistencia hacia las bacterias.

La mortalidad estuvo determinada por la reacción surgida principalmente por el efecto ante las bacterias. Se consideró que en las primeras horas post-infección $(5 \mathrm{~h})$ los camarones tuvieron una respuesta acelerada (hiper-reacción) ante los patógenos invasores lo que tal vez generó una deficiencia inmunológica y se vio representada con una mayor mortalidad a las $10 \mathrm{~h}$; efecto asociado a lo expresado por Maldonado (2003) y Cuéllar (2008). De acuerdo a lo anterior en ambos bioensayos se observó que los camarones que mantuvieron una menor mortalidad al inicio presentaron mayores muertes al final, al contrario, el grupo de camarones que en inicio declinaron con mayor facilidad lograron mantener una mayor sobrevivencia.

Las células circulantes pueden ocasionar respuestas inflamatorias que amplifican las reacciones inmunes ante una invasión microbial, lo que libera sustancias autolíticas y citotóxicas inducidas de una manera no específica (Maldonado 2003), como el caso de la peroxinectina que se genera a partir de la activación del sistema proPO (Cuéllar 2008). Dicho autor menciona que las moléculas altamente tóxicas que se producen para combatir los agentes invasores, también generan daño al tejido del hospedero. Dado lo anterior, se estableció que los camarones que soportaron la reacción inicial presentaron mejores expectativas de sobrevivencia y relacionado estrechamente a los tratamientos empleados.

La patogenicidad de las bacterias determinó la mortalidad de los camarones, aunque estuvo asociada indirectamente a la cantidad de bacterias inoculadas. Lo anterior quedó demostrado en el estudio realizado por Roque et al. (1998). En otro estudio se observó cuando se utilizó V. penaeicida (Pantoja 2005), mortalidades del 100, 95 y $90 \%$ cuando se utilizaron 

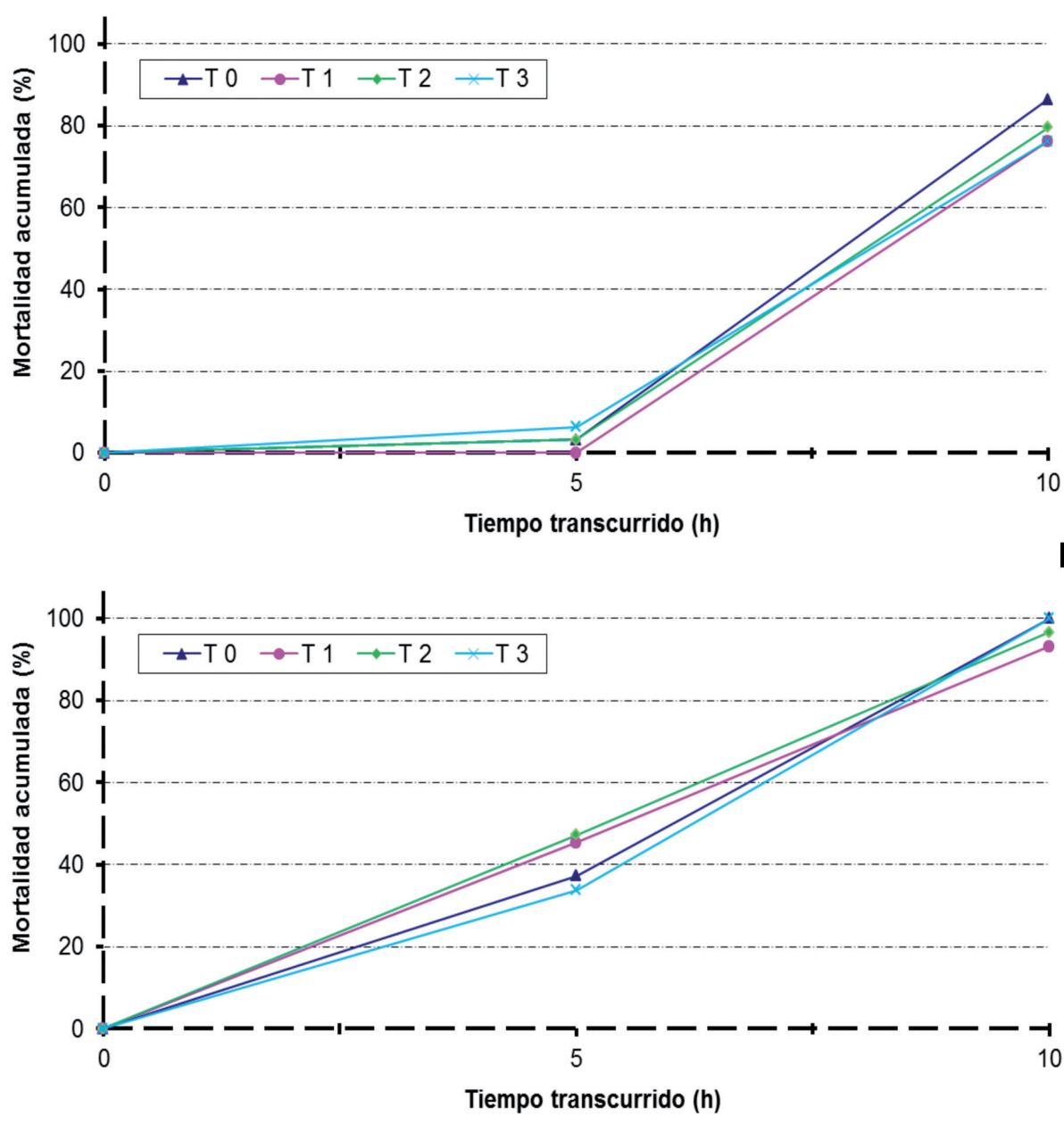

Figura 2. Medias de las mortalidades acumuladas obtenidas de Litopenaeus vannamei infectados con Vibrio parahaemolyticus y después de ser alimentados con una dieta control (T0), mananooligosacáridos (T1), ajo (T2) y extractos de plantas (T3). Costa Rica. 2011.

A) Infección de seis días, donde se inyectaron $1 \times 10^{6}$ UFC/camarón. B) Infección de catorce días, donde se inyectaron $3 \times 10^{6} \mathrm{UFC} /$ camarón.

concentraciones de $5 \times 10^{5}, 1 \times 10^{4}$ y $5 \times 10^{4}$ UFC/camarón, respectivamente, $\mathrm{y}$ asociado a lo expuesto con anterioridad.

La mayoría de investigaciones realizaron infecciones por medio de inmersión de camarones con preparaciones que contenían Vibrio sp. (Scholz et al. 1999, Trujillo et al. 2005, Heidarieh et al. 2010). Contrario a lo anterior, el presente estudio utilizó

ISSN: 1021-7444 como técnica la inoculación por medio de inyección intramuscular (Roque et al. 1998), debido a su rapidez de acción y obtención de información en un periodo corto de experimentación. Sin embargo, al comparar la información obtenida en esta investigación, al final en la mayoría de los casos se presentaron altas mortalidades para el tratamiento que ejerció como control; lo que significaría que una diferencia en la composición 
de la dieta convencional ocasionaría un cambio en la capacidad de respuesta del camarón, ante una situación que lograra poner en riesgo su salud.

Lo expuesto anteriormente demuestra que al utilizar en la dieta algún aditivo obtenido a partir de un producto natural, puede lograr un cambio considerable en la salud de los camarones cuando están expuestos a niveles excesivos no solo de bacterias sino también de virus, hongos y parásitos (Barracco et al. 2008). Dichos autores también mencionan que los inmunoestimulantes tienen el propósito de aumentar la resistencia natural, a la vez que minimizan el uso de agentes terapéuticos químicos como antibióticos; del mismo modo, deja claro que no se quiere un sistema inmunológico activo continuamente sino un estado de mayor inmunocompetencia, donde los camarones tengan mayor capacidad y rapidez en su respuesta ante patógenos.

$\mathrm{Al}$ analizar todas las variables en conjunto (hemograma, coagulación, UFC y mortalidad acumulada) e individualmente a los seis y catorce días como lo realizó Rodríguez et al. (2000), se observó que en el bioensayo de más días, T2 fue mejor en CTH, UFC y coagulación, mientras que en la sobrevivencia final estuvo entre los menores porcentajes junto a T1. A los seis días T1 mostró los mejores valores en todos los parámetros inmunológicos analizados, pero con valores muy cercanos a los otros tratamientos.

Con respecto a los parámetros inmunológicos, las ganancias de pesos y las conversiones alimenticias presentaron diferencias significativas entre tratamientos $(\mathrm{P}<0,05)$ en el periodo de seis días del bioensayo 1; no obstante en la fase que duró catorce días las variables evaluadas no fueron estadísticamente diferentes $(\mathrm{P}>0,05)$.

\section{Ganancia de peso}

Los pesos finales obtenidos del bioensayo que duró seis días, demostraron que el tratamiento conformado por T2 $(54,3 \pm 1,9 \mathrm{~g})$ fue estadísticamente mejor que $\mathrm{T} 3(\mathrm{P}<0,05)$. Sin embargo, no fue diferente del tratamiento control ni de la dieta que contenía T1. A la vez, los resultados obtenidos de $\mathrm{T} 3(47,0 \pm 6,3 \mathrm{~g})$ fueron similares a T0 y T1 (Cuadro 2A).

Los camarones alimentados con T2 obtuvieron un valor del 8,8 $\mathrm{g}$ de ganancia de peso, estos fueron superiores en más de un $15 \%$ con respecto a los demás
Cuadro 2. Medias del peso inicial, final y ganancia de peso (g) obtenidas de Litopenaeus vannamei infectado con Vibrio parahaemolyticus y después de ser alimentados con diferentes dietas. Costa Rica. 2011.

\begin{tabular}{ccccc}
\hline Tratamiento & PI & PF & GP & $\Delta \%$ \\
\hline T0 & 49,0 & 48,8 & $-0,2 \mathrm{~b}$ & $-0,4$ \\
T1 & 47,0 & 49,3 & $2,3 \mathrm{~b}$ & 4,9 \\
T2 & 45,5 & 54,3 & $8,8 \mathrm{a}$ & 1,3 \\
T3 & 46,0 & 47,0 & $1,0 \mathrm{~b}$ & 2,1 \\
\hline & & & & \\
\hline Tratamiento & PI & $\mathbf{P F}$ & $\mathbf{G P}$ & $\Delta \%$ \\
\hline T0 & 52,0 & 62,0 & 10,0 & 19,2 \\
T1 & 55,0 & 65,3 & 10,3 & 18,7 \\
T2 & 51,8 & 59,0 & 7,3 & 14,0 \\
T3 & 52,8 & 61,0 & 8,3 & 15,6 \\
\hline
\end{tabular}

A

B

Letras diferentes en una misma columna difieren entre sí $(\mathrm{P}<0,05)$.

A) Infección de seis días donde se inyectaron $1 \times 10^{6} \mathrm{UFC} /$ camarón.

B) Infección de catorce días donde se inyectaron $3 \times 10^{6} \mathrm{UFC} /$ camarón.

T0: control, T1: manano-oligosacáridos, T2: ajo, T3: extractos de plantas.

PI: peso inicial, PF: peso final, GP: ganancia de peso, D\%: incremento porcentual.

tratamientos evaluados y donde se promediaron datos porcentuales similares al periodo experimental que se extendió por catorce días (Cuadro 2B). Contrario a lo anterior, los tratamientos restantes resultaron en valores inferiores al 5\% de ganancia de peso e inclusive se obtuvo un valor negativo para esta variable en T0 $(-0,4 \%)$, lo que indica un autoconsumo por parte de los camarones. Posiblemente se dio por estrés producido por el manejo general y por los niveles reducidos de oxígeno que se presentaron esporádicamente, que habrían provocado una inadecuada conversión del alimento consumido o una reducción de la ingesta. Por consiguiente y dado lo anterior, se podrían determinar en general que sí existieron efectos positivos debido a la inclusión de los diferentes aditivos en las dietas.

Durante el periodo de catorce días se promediaron ganancias de peso entre 7,25 $\pm 4,03$ y $10,25 \pm 2,22 \mathrm{~g}$. Aunque no se dieron diferencias estadísticas (Cuadro 
2B), las medias reflejaron valores por encima de los esperados en la realidad, ya que en condiciones normales de cultivo se esperan incrementos semanales de un gramo para cada animal (López 2010) y al finalizar la fase experimental se obtuvo un incremento promedio de 4,5 g en cada semana. Lo anterior se debió probablemente a las condiciones idóneas en las que se desarrolló esta etapa de la investigación asociado a los aditivos incorporados en el alimento concentrado.

Al utilizar dietas con $S$. cerevisiae, $\beta$-glucanos y Phaffia rhodozyma, se demostró (Scholz et al. 1999) que después de siete semanas no se presentaron diferencias significativas en los pesos finales de los animales, sin embargo la biomasa final si presentó diferencias entre los tratamientos, donde se obtuvo los mejores resultados por parte de la dieta compuesta por $\beta$-glucano. Al considerar el origen natural de los aditivos anteriores y al asociarlos con los evaluados en la investigación realizada, se enfatiza la importancia de este tipo de productos para lograr un incremento acelerado en las ganancias de peso de los camarones.

Cuando se analizó la inclusión (Dantas et al. 2009) de probióticos (Bacillus subtilis y Bacillus licheniformis), para evaluar su efecto ante la infección de $V$. harveyi, el tratamiento control (sin probiótico) obtuvo las mejores ganancias de peso, considerando la condición natural (autótrofos y heterótrofos) de los camarones y al valorar la posibilidad de que ya estaban acondicionados a la presencia de microbios. De lo anterior se entiende, que existe la necesidad de conocer el comportamiento alimenticio y las condiciones generales de cultivo antes de iniciar pruebas de este tipo y que sean similares a las presentadas en estos bioensayos. Sin embargo, de los resultados obtenidos en el periodo de catorce días (Cuadro 2B), las ganancias de peso demuestran que fueron mejores a las presentadas normalmente en los estanques de cultivo, lo que hace pensar que un cambio en las condiciones actuales de manejo en los estanques muestreados, podrían ocasionar mejorías en los parámetros zootécnicos que generalmente se monitorean y cuyo resultado final sería la maximización de las ganancias económicas.

\section{Conversión alimenticia}

Según la prueba de Duncan las medias de T1 y T2 fueron estadísticamente diferentes $(\mathrm{P}<0,05)$ para la conversión alimenticia en el periodo determinado por seis días; donde el tratamiento al que se le incorporó ajo fue mejor que el que contenía manano-oligosacáridos, donde se obtuvo una conversión alimenticia de $1,40 \pm 0,63$ y $4,53 \pm 2,25$ respectivamente. Por otro lado, el tratamiento control y T3 $(3,23 \pm 1,16)$ no fueron diferentes de T1 ni de T2. Respecto al bioensayo 2 , las medias fueron $4,82 \pm 2,08 ; 3,17 \pm 1,20 ; 3,12 \pm 0,73$ y 2,96 $\pm 0,90$ respectivamente para $\mathrm{T} 2, \mathrm{~T} 0, \mathrm{~T} 1$ y T3.

Los resultados del tratamiento control en el bioensayo que duró seis días presentaron una conversión alimenticia muy variable, lo que reflejó una dispersión muy elevada de los datos analizados; lo anterior posiblemente se debió a que en algunas de las repeticiones los camarones tuvieron una reducida ganancia de peso, asociada al estrés provocado por el manejo y a los episodios esporádicos que sucedieron en la disminución del oxígeno. De los resultados del trabajo de Rodríguez et al. (2000), se desprende que la condición fisiológica de los animales sufre alteraciones luego de su estadía en los tanques de experimentación, semejante a la misma conclusión para la presente investigación.

Por otro lado, Scholz et al. (1999) no encontraron diferencias en la tasa de conversión alimenticia al utilizar en las dietas $S$. cerevisiae, $\beta$-glucanos y Phaffia rhodozyma, contrario a lo presentado en esta investigación, donde queda claro un efecto de los tratamientos suministrados a los seis días de evaluación, liderado ampliamente por el ajo. Respecto a este tratamiento, no presentó por sí mismo un efecto directo en la conversión del alimento ni en la ganancia de peso; sino más bien y de acuerdo a lo expuesto por Prieto et al. (2005) y lo obtenido en estos bioensayos, podría mejorar a corto plazo la absorción intestinal, al eliminar las bacterias o los parásitos presentes en esta región; a la vez, al influir positivamente en la inmunología, lograría mejorar la condición sanitaria del camarón y como resultado final una mayor capacidad de ingestión de los alimentos.

En términos generales, se podrían considerar a partir de los datos numéricos, los tratamientos compuestos por T1 y T2 como los mejores inmunomoduladores, si se comparan entre sí todos los resultados obtenidos de esta investigación preliminar. Se recomienda a partir de la información obtenida que para episodios repentinos de infección bacterial se aplique manano-oligosacáridos en el alimento en periodos menores a una semana. Por otro lado, cuando se den problemas críticos de infección y con mayor duración, se utilice ajo en la ración de forma constante hasta lograr una disminución adecuada en los niveles de infección. 


\section{AGRADECIMIENTOS}

A la Estación Experimental Alfredo Volio Mata (EEAVM) y a la Cooperativa Nacional de Productores de Sal R.L., por el aporte económico. A Kenneth Dirst por el apoyo técnico. Al Centro de Investigación en Ciencias del Mar y Limnología (CIMAR) por las facilidades otorgadas en el uso de las instalaciones y al Parque Marino del Pacífico por la donación del agua de mar. A la Dra. Rocío González del Laboratorio Nacional de Servicios Veterinarios (LANASEVE) y al Dr. Norman Rojas de Microbiología Médica de la UCR por el apoyo en los análisis y material facilitado.

\section{LITERATURA CITADA}

Álvarez, J; Austin, B; Alvárez, A; Agurto, C. 2000. Especies de Vibrio y Aeromonas aisladas del intestino de camarones marinos sanos silvestres y cultivados en Venezuela. Veterinaria Tropical 25(1):5-27.

Balcázar, JL. 2002. Uso de probióticos en acuicultura: Aspectos generales. In I Congreso Iberoamericano Virtual de Acuicultura. 877-881 p. (en línea). Consultado 17 julio 2010. Disponible en http://www. civa2002.org

Barracco, MA; Perazzolo, LM; Rosa, RD. 2008. Inmunología del camarón. In Morales, V; Cuéllar-Ánjel, J. eds. Guía técnica - patología e inmunología de camarones penaeidos. Programa CYTED Red II-D Vannamei. Panamá, Rep. de Panamá. 270 p.

Benchaar, C; Petit, H; Berthiaume, R; Ouellet, D; Chiquette J; Chouinard, P. 2007. Effects of essential oils on digestion, ruminal fermentation, rumen microbial populations, milk production, and milk composition in dairy cows fed alfalfa silage or corn silage. J. Dairy Sci. 90(2): 886-897.

Burge, EJ; Madigan, DJ; Burnett, LE; Burnett, KG. 2007. Lysozyme gene expression by hemocytes of Pacific white shrimp, Litopenaeus vannamei, after injection with Vibrio. Fish Shellfish Immunol. 22:327-339.

Burgents, JE; Burnett, LE; Stabb, EV; Burnett, KG. 2005. Localization and bacteriostasis of Vibrio introduced into Pacific white shrimp, Litopenaeus vannamei. Dev. Comp. Immunol. 29:681-691.

Cerenius, L; Söderhäll, K. 2004. The prophenoloxidaseactivating system in invertebrates. Immunol. Rev. 198:116-126.
Chang, CF; Chen, YH; Su, MS; Liao, IC. 2000. Immunomodulation by dietary $\beta$-1, 3-glucan in the brooders of the black tiger shrimp Penaueus monodon. Fish Shellfish Immunol. 10:505-514.

Cuéllar, J. 2008. Métodos de diagnósticos de enfermedades en camarones marinos de cultivo. p. 1-54. In Morales, V; Cuéllar-Ánjel, J. eds. Guía técnica - Patología e inmunología de camarones penaeidos. Programa CYTED Red II-D Vannamei, Panamá, República de Panamá. $270 \mathrm{p}$.

Cuéllar-Ánjel, J; Lara, C; Morales, V; De Gracia, A; García Suárez, O. 2010. Manual de buenas prácticas de manejo para el cultivo del camarón blanco Penaeus vannamei. OIRSA- OSPESCA, C.A. Panamá. p. 132.

Curiquén, E; González, H. 2006. Uso de manano oligosacáridos como una alternativa a los antibióticos. Circular de Extensión Técnico Ganadera 32:41-50.

Dantas, D; Alves, E; Rego, M; Soares, R; Peixoto, S; Gálvez, A. 2009. Desempenho do Litopenaeus vannamei (Boone, 1931) cultivado com uso de probiótico quando submetido à infecção por Vibrio harveyi. Rev. Bras. Cienc. Agrar. 4(1):85-90.

Decamp, O; Moriarty, DJ; Levens, P. 2008. Probiotics for shrimp larviculture: review of field data from Asia and Latin America. Aquacult. Res. 39: 334-338.

FAO (Food and Agriculture Organization). 2010. Penaeus vannamei (Boone, 1931). Programa de información de especies acuáticas. Departamento de Pesca y Acuicultura (en línea). Consultado 30 julio 2010. Disponible en http://www.fao.org/fishery/culturedspecies/Litopenaeus_vannamei/es

Ganesh, EA; Das, S; Chandrasekar, K; Arun, G; Balamurugan, S. 2010. Monitoring of total heterotrophic bacteria and Vibrio spp. in an aquaculture pond. Curr. Res. J. Biol. Sci. 2(1):48-52.

Gómez, B; Tron-Mayen, L; Roque, A; Turnbull, JF; Inglis, V; Guerra, AL. 1998. Species of Vibrio isolated from hepatopancreas, haemolymph and digestive tract of a population of healthy juvenile Penaeusvannamei. Aquaculture 163:1-9.

Gómez, B; Roque, A; Guerra, AL. 2001. Enfermedades infecciosas más comunes en la camaronicultura en México y el impacto de uso de antimicrobianos. In Páez-Osuna, F. ed. Camaronicultura y Medio Ambiente. UNAM. Mazatlán, Sinaloa México. p. 315-346.

Gullian, M; Rodríguez, J. 2002. Estudio de las cualidades inmunoestimulantes de nuevas bacterias probióticas asociadas al cultivo de Litopenaeus vannamei. In 
Contribuciones del CENAIM durante el VI Congreso Ecuatoriano de Acuicultura 8(1):47-49.

Haws, MC; Boyd, CE; Green, BW. 2001. Buenas prácticas de manejo en el cultivo de camarón en Honduras. Coastal Resources Center.University of Rhode Island. Kingston, United States. 96 p.

Heidarieh, M; Afsharnasab, M; Soltani, M; Dashtyannasab, A; Rajabifa, RS; Sheikhzadeh, N; Tamimi, AH. 2010. Effects of Ergosan and Vibromax to prevent Vibriosis and WSSV in Litopenaeus vannamei. J. Fish. Aqua. Sci. 5(2):120-125.

Hsu, SW; Chen, JC. 2007. The immune response of white shrimp Penaeus vannamei and its susceptibility to Vibrio alginolyticus under sulfide stress. Aquaculture 271:61-69.

Ibarra, JC; Reyes, J; Galavíz, L; Molina, Z; Luna, C. 2003. Vibriosis asociadas al cultivo de camarón Litopenaeus vannamei. In IX Congreso de Ciencia de los Alimentos y V Foro de Ciencia y Tecnología los Alimentos. Guanajuato, México. p. 426-430.

Jiravanichpaisal, P; Lee, BL; Söderhäll, K. 2006. Cellmediated immunity in arthropods: Hematopoiesis, coagulation, melanization and opsonization. Immunobiology 211:213-236.

Johansson, MW; Keyser, P; Sritunyalucksana, K; Söderhäll, K. 2000. Crustacean haemocytes and haematopoiesis. Aquaculture 191:45-52.

Kannapiran, E; Ravindran, J; Chandrasekar, R; KalaiarasI, A. 2009. Studies on luminous, Vibrio harveyi associated with shrimp culture system rearing Penaeus monodon. J. Environ. Biol. 30(5):791-795.

Lee, SY; Söderhäll, K. 2002. Early events in crustacean innate immunity. Fish Shellfish Immunol. 12:421-437.

López, O. 2010. Técnicas de producción de camarón marino (Litopenaeus vannamei) en Costa Rica. Ecag Informa. 52:30-32.

Maldonado, M. 2003. Respuesta inmunitaria en familias de Litopenaeus vannamei, bajo condiciones de infección con WSSV y el efecto de la adición de $\beta-1,3$ glucanos. Tesis de grado previa a la obtención del título de Magíster en Ciencias. Escuela Superior Politécnica del Litoral. Facultad de Ingeniería Marítima y Ciencias del Mar. Guayaquil, Ecuador. 31 p.

Mayer, E. 2010. Evaluation of Vibrio control with a multispecies probiotic in shrimp aquaculture. Internat. Aquafeed 13(4):16-20.

Montserrat, E; Herrera, F. 2000. Alteraciones histológicas del hepatopáncreas en juveniles de Farfantepenaeus brasiliensis (Latreille 1817) (Crustacea: Penaeidae) experimentalmente infectados con Vibrio Alginolyticus. Saber, Universidad de Oriente, Venezuela 12(1):14-20.

Morales, MS. 2008. Enfermedades bacterianas. In Morales, V; Cuéllar-Anjel, J. eds. 2008. Guía técnica - patología e inmunología de camarones penaeidos. Programa CYTED Red II-D Vannamei, Panamá, Rep. de Panamá. p. 117-134.

Pantoja, CR. 2005. Kona line SPF shrimp, Vibrio penaeici$d a$ candidates for bacterial challenge model. Global Aquacul. Advocate 8(3):82-83.

Prieto, A; Auro, A; Fernández, A; Pérez, MB. 2005. El empleo de medicina natural en el control de enfermedades de organismos acuáticos y potencialidades de uso en Cuba y México. Tip Rev. Esp. Cienc. Quím. Biol. $8(1): 38-49$.

Rodríguez, J; Cedeño, R; Molina, C; Otero, V; Valenzuela, E; Sotomayor, MA. 2000. Efecto de la calidad de la dieta sobre la respuesta inmune del camarón Penaeus vannamei. In Cruz, LE; Ricque, D; Tapia, M; Olvera, M; Civera, R. eds. Avances en nutrición acuícola V. Memorias del V Simposium Internacional de Nutrición Acuícola. Mérida, Yucatán, México. p. 57-71.

Rodríguez, J; Le Moullac, G. 2000. State of the art immunological tools and health control of penaeid shrimp. Aquaculture 191:109-119.

Rojlorsakul, P; Boonsaeng, V; Panbangred, W; Suthienkul, O; Pasharawipas, T; Flegel, TW. 1998. Detection of Vibrio parahaemolyticus in shrimp haemolymph by DNA hybridazation and PCR amplification. In Flegel, TW. ed. Advances in shrimp biotechnology. National Center for Genetic Engineering and Biotechnology, Bangkok. p. 227-234.

Roque, A; Gómez, B; Guerra, AL. 1998. Standardisation of three techniques for experimental Vibrio infections in the marine shrimp Penaeus vannamei. In Flegel, TW. ed. Advances in shrimp biotechnology. National Center for Genetic Engineering and Biotechnology. Bangkok. Thailand. p. 199-203.

SAS (Statistical Analysis System). 2003. SAS User's guide. SAS. Inst. Inc. Cary, NC, USA. 212 p.

Scholz, U; García, G; Ricque, D; Cruz, LE; Vargas, F; Latchford, J. 1999. Enhancement of vibriosis resistance in juvenile Penaeus vannamei by supplementation of diets with different yeast products. Aquaculture 176:271-283.

Smith, VJ; Brown, JH; Hauton, C. 2003. Immunostimulation in crustaceans: does it really protect against infection? Fish Shellfish Immunol. 15:71-90. 
Trujillo, T; Aguirre, G; Sánchez, G; Rabago, J. 2005. Patogenicidad de Vibrio parahaemolyticus y Vibrios sp. en juveniles de camarón blanco del Pacífico (Litopenaeus vannamei Boone, 1931). Cienc. Mar IX(27):11-18.

Villamar, CA. 2000. Acuicultura orgánica-ecológica: aplicación de productos naturales en sustitución de químicos en los procesos de cría de camarones en cautiverio. Rev. AquaTIC 10:27-30.

Yeh, ST; Chen, JC. 2008. Immunomodulation by carrageenans in the white shrimp Litopenaeus vannamei and its resistance against Vibrio alginolytocus. Aquaculture 276:22-28. 
